\title{
Subclinical Hypothyroidism Increases the Requirement of Renal Replacement Therapy After Cardiac Surgery
}

\author{
Naim Boran Tumer, ${ }^{1}$ Atike Tekeli Kunt, ${ }^{2}$ Hatice Keles, ${ }^{2}$ Kanat Ozisik, ${ }^{1}$ Serdar Gunaydin ${ }^{1}$ \\ ${ }^{1}$ University of Health Sciences, Ankara Numune Education and Research Hospital, Department of Cardiovascular Surgery, \\ Ankara, Turkey; ${ }^{2}$ Kirikkale University, Medical School, Department of Cardiovascular Surgery, Kirikkale, Turkey; ${ }^{3}$ Department of \\ Nephrology, Kirikkale University, Medical School, Kirikkale, Turkey
}

\section{ABSTRACT}

Background: Subclinical or biochemically diagnosed hypothyroidism ( $\mathrm{SCH})$ is defined as an elevated serum thyroid-stimulating hormone (TSH) with normal free thyroxine (FT4) levels. Thyroid hormones play a major role in the normal function of the heart and vascular physiology. Atherosclerosis, increased systemic vascular resistance, and decreased arterial compliance are common pathophysiological changes that may occur in hypothyroidism. Acute kidney injury (AKI) is one of the devastating complications after cardiac surgery. Age, diabetes mellitus (DM), preexisting renal dysfunction, hypertension, impaired left ventricular function, and severe arteriosclerosis are the major risk factors for the development of AKI. The purpose of the current study was to analyze the influence of $\mathrm{SCH}$ on $\mathrm{AKI}$ and the requirement of renal replacement therapy (RRT) after isolated coronary artery bypass graft surgery (CABG).

Methods: We retrospectively reviewed the prospectively collected data of 336 adult patients who underwent isolated CABG surgery with normal renal function (baseline serum creatinine value $<1.4 \mathrm{mg} / \mathrm{dL}$ ) from January 2017 to January 2019. The patients were divided into two groups either having the diagnosis of SCH (Group I, N = 47) or not (Group II, $\mathrm{N}=289$ ). SCH was diagnosed based on preoperative serum TSH and FT4 levels. Kidney injury was interpreted, according to RIFLE classification. The effect of SCH on AKI and the need for RRT after CABG was determined using logistic regression analysis and the results were expressed as odds ratio $(\mathrm{OR})$ with a $95 \%$ confidence interval $(\mathrm{CI})$. A $P$ value $<$ .05 was considered statistically significant.

Results: Subclinical hypothyroidism was diagnosed in $14 \%$ of all patients. Postoperative AKI occurred in 15 patients $(31.9 \%)$ in Group I, whereas there were 42 patients $(14.5 \%)$ in Group II. On logistic regression analysis, the presence of $\mathrm{SCH}$ was shown to be associated with an increased incidence of postoperative AKI (OR, 0.363; 95\% CI, 0.181-0.727; $P=.004)$. RRT was used in $2.97 \%$ of patients (seven patients

Received May 12, 2020; accepted fune 24, 2020.

Correspondence: Atike Tekeli Kunt, MD, PhD, Professor of Cardiovascular Surgery Kirikkale University, Medical School, Department of Cardiovascular Surgery, Kirikkale, Turkey, Ankara Yolu 7, Km, 71450 Yahşihan/Kırıkkale; +90-532-746-78-69 (e-mail: atikemd@gmail.com). in Group I and three patients in Group II, $P<.001)$. The 30 -day mortality was $2.1 \%$.

Conclusion: The presence of SCH seems to be associated with an increased incidence of AKI and increased requirement for RRT after cardiac surgery.

\section{INTRODUCTION}

Subclinical or biochemically diagnosed hypothyroidism $(\mathrm{SCH})$ is defined as elevated serum thyroid-stimulating hormone (TSH) with normal free thyroxine (FT4) levels [Kim 2014].

The prevalence of SCH ranges from $4 \%$ to $15 \%$ in the general population, being higher in women and older adults [Garber 2012]. It is suggested in the literature that both overt and subclinical hypothyroidism increase the risk of atherosclerosis and coronary artery disease [Saif 2018; Mousa 2020]. It also is reported that both overt and subclinical hypothyroidism are associated with hypotension, increased vascular resistance, and decreased sodium reabsorption, which leads to volume contraction and reduced renal blood flow and low glomerular filtration rate [Wikström 1998; Liu 2014; Michael 1972; Chang 2018]. Recent reports suggested that SCH was associated with acute kidney injury (AKI) in patients with

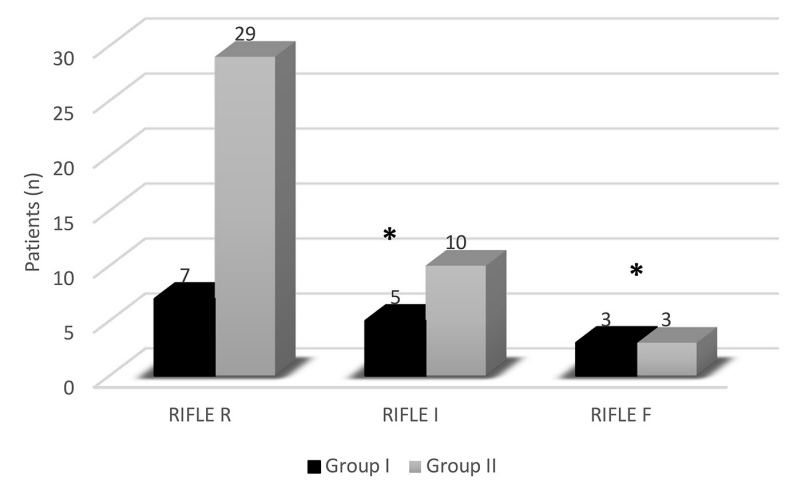

Comparison of Group I and Group II, according to RIFLE classification. *statistically significant, $P=.044$ and $P=.038$, respectively. Group I: Subclinical hypothyroid patients, Group II: Patients with normal thyroid functions. 
Table 1. RIFLE Classification

\begin{tabular}{lr}
\hline GFR Criteria & Urine Output Criteria \\
\hline Risk Increased plasma creatinine $\times 1.5$ & $<0.5 \mathrm{~mL} / \mathrm{kg}^{1} / \mathrm{h}^{1} \times 6 \mathrm{hours}$ \\
Injury Increased plasma creatinine $\times 2$ & $<0.5 \mathrm{~mL} / \mathrm{kg}^{1} / \mathrm{h}^{1} \times 12 \mathrm{hours}$ \\
Failure Increased plasma creatinine $\times 3$ or acute plasma creatinine $\geq 350 \mu \mathrm{mol} / \mathrm{L}$ or acute rise $\geq 44 \mu \mathrm{mol} / \mathrm{L}$ & $<0.3 \mathrm{~mL} / \mathrm{kg}^{1} / \mathrm{h}^{1} \times 24 \mathrm{hours}$ \\
\hline
\end{tabular}

Loss Persistent acute renal failure $=$ complete loss of kidney function $>4$ weeks

ESKD End-stage kidney disease (>3 months)

ESKD indicates end-stage kidney disease; GFR, glomerular filtration rate.

diabetes, coronary artery disease, and chronic kidney disease [Kim 2014; Zhang 2017; Zahler 2019].

Acute kidney injury is one of the devastating complications after cardiac surgery. Age, diabetes mellitus (DM), preexisting renal dysfunction, hypertension, impaired left ventricular function, and severe arteriosclerosis of the aorta are the major risk factors for the development of AKI [Doddakula 2007; Weerasinghe 2001; Chertow 1997]. Intraoperatively, inflammatory response syndrome due to cardiopulmonary bypass (CPB), nonpulsatile flow, and renal hypoperfusion also are important causes of AKI [Suen 1998; Hall 1997]. The purpose of the current study was to analyze the influence of SCH on $\mathrm{AKI}$ and the requirement of renal replacement therapy (RRT) after isolated coronary artery bypass graft surgery (CABG).

\section{MATERIALS AND METHODS}

After we received institutional review board approval, we retrospectively reviewed the prospectively collected data of 378 adult patients, who underwent isolated CABG surgery with normal renal function (baseline serum creatinine value $<1.4 \mathrm{mg} / \mathrm{dl}$ ) from January 2017 to January 2019. All patients previously granted permission for the use of their medical records for research purposes. The clinical data of the patients included demographic data, laboratory data, length of stay, in-hospital complications, and mortality. Subclinical hypothyroidism was defined as TSH levels $\geq 4.1 \mathrm{mIU} / \mathrm{L}$ in the presence of normal FT4 levels (0.7-1.8 ng/dl), and the euthyroid state was defined as normal level of TSH $(0.4-4.1 \mathrm{mIU} / \mathrm{L})$ and normal FT4 levels (0.7-1.8 ng/dl). Preoperative measurement of thyroid functions routinely were performed for all patients undergoing cardiac surgery in our clinic. Patients with overt hypothyroidism, overt hyperthyroidism, and subclinical hyperthyroidism and patients receiving thyroid replacement therapy were excluded from the study $(\mathrm{N}=42)$. The patients $(\mathrm{N}=336)$ were then divided into two groups either having the diagnosis of SCH (Group I, N = 47) or not (Group II, $\mathrm{N}=289$ ). The primary outcome was the development of AKI. Kidney injury was interpreted according to RIFLE classification [Bellomo 2004], explained as RIFLE R: risk; RIFLE I: injury; RIFLE F: failure; RIFLE L: loss; and RIFLE E: end-stage kidney disease. (Table 1) Patients who were on either hemodialysis or peritoneal dialysis, patients with emergent surgery, recent myocardial infarction, peripheral vascular disease, and patients undergoing operations other than or in conjunction with CABG were excluded from the study.

CABG procedure: All operations were performed in a standardized approach by a Terumo roller pump (Terumo Advanced Perfusion System 1, USA), membrane oxygenators (Inspire 8, LivaNova Sorin Group, Italy). Mild to moderate $\left(28-32^{\circ} \mathrm{C}\right)$ hypothermia and pulsatile flow of $2.2-2.4 \mathrm{~L} /$ $\mathrm{m}^{2}$ were used. Myocardial protection was achieved with tepid antegrade blood cardioplegia, and a "hot shot" (250-500 ml) was delivered just before the removal of the aortic crossclamp. The perfusion pressure was kept over $70 \mathrm{mmHg}$ at all times. Induction and maintenance of general anesthesia with endotracheal intubation were standardized in all the patients (fentanyl, midazolam, and isoflurane in oxygen with air). The same surgical team performed all of the operations.

Postoperative management: Postoperatively, patients were followed in the intensive care unit (ICU) according to protocols of our institution. Electrocardiography, systemic mean arterial pressure, central venous pressure, pulmonary artery and wedge pressures, cardiac output and index, arterial blood gases, chest tube output, and hourly urine output were monitored. Serum electrolytes were measured in conjunction with arterial blood gas measurement. Fluid and electrolyte imbalances were immediately corrected with appropriate management. Hematocrit values $<25 \%$ were corrected with erythrocyte suspension administration postoperatively. Daily blood urea nitrogen, serum, and urea creatinine and serum electrolytes uniformly were measured in all patients until discharge from the hospital. Preoperative and postoperative creatinine clearances and peak creatinine clearance were calculated, according to the formulations reported in the literature [Lassnigg 2000; Cockcroft 1976]. The indication criteria for RRT, hyperkalemia $(>6 \mathrm{mmol} / \mathrm{l})$, oliguria $<0.5 \mathrm{ml} / \mathrm{kg} / \mathrm{h}$ for 12 hours or anuria, and metabolic acidosis, were determined by our nephrologist. Vascular access for RRT was with a dual lumen catheter via a central venous vein. Patients were heparinized to achieve activated clotting time of 200 seconds. Fresenius polysulfone filter (Fresenius Medical care AG, Bad Homburg, Germany) was used for filtration.

Statistical analysis: All statistics were performed using SPSS version 18.0 for Windows (IBM Corporation, New York, USA). Continuous variables were expressed as mean \pm 
Table 2. Baseline and perioperative characteristics of patients.

\begin{tabular}{|c|c|c|c|}
\hline Age, years & $64.9 \pm 12.1$ & $60.9 \pm 10.1$ & .015 \\
\hline Body mass index, $>30 \mathrm{~kg} / \mathrm{m} 2, \%$ & 51.1 & 30.1 & .007 \\
\hline Hypertension, \% & 61.7 & 63.7 & .871 \\
\hline Diabetes, \% & 46.8 & 33.2 & .098 \\
\hline Metabolic syndrome, \% & 36.2 & 16.6 & .004 \\
\hline LV function, \% & $56.4 \pm 9.2$ & $54.7 \pm 8.9$ & .239 \\
\hline CPB time, $\min$ & $105.7 \pm 27.5$ & $113.0 \pm 35.5$ & .178 \\
\hline Cross-clamp time, $\min$ & $59.8 \pm 19.7$ & $64.3 \pm 22.9$ & .207 \\
\hline Free $\mathrm{T} 4, \mathrm{ng} / \mathrm{dl}$ & $1.0 \pm 0.3$ & $0.9 \pm 0.2$ & .063 \\
\hline
\end{tabular}

Data are presented as mean \pm SD where indicated. CPB: cardiopulmonary bypass; LV: left ventricle, TSH: thyroid stimulating hormone. *Chi-square and unpaired Student $t$ tests. Statistically significant values are $P<.05)$.

SD and were compared by unpaired Student's t-test or the chi-squared test. The effect of preoperative $\mathrm{SCH}$ on AKI after $\mathrm{CABG}$ was determined using logistic regression analysis and the results were expressed as odds ratio (OR) with a $95 \%$ confidence interval (CI). A $P$-value $<.05$ was considered statistically significant.

\section{RESULTS}

Patient demographics and perioperative data are shown in Table 2. (Table 2) Among the patient characteristics and perioperative data, female sex, age, body mass index, metabolic syndrome (MetS), and TSH levels significantly were higher in Group I. Other data did not show statistically significant differences between the groups. Subclinical hypothyroidism was diagnosed in $14 \%$ of all patients. Postoperative AKI occurred in 15 patients $(31.9 \%)$ in Group I, whereas there were 42 patients $(14.5 \%)$ in Group II with postoperative AKI. On logistic regression analysis, the presence of SCH was shown to be associated with an increased incidence of postoperative AKI (OR, 0.363; 95\% CI, 0.181-0.727; $P=.004)$. Multivariate logistic regression analysis revealed that DM (OR, 4.975; 95\% CI, 2.707-9.145; $P<.001$ ), obesity (BMI $\left.>30 \mathrm{~kg} / \mathrm{m}^{2}\right)(\mathrm{OR}, 3.878 ; 95 \% \mathrm{CI}, 2.148-7.001 ; P<.001)$, and MetS (OR, 3.817; 95\% CI, 2.048-7.115; $P<.001)$ were other independent risk factors for AKI after isolated CABG.

The preoperative mean serum creatinine was $0.93 \pm$ $0.18 \mathrm{mg} / \mathrm{dL}$ in Group I and $0.91 \pm 0.21 \mathrm{mg} / \mathrm{dL}$ in Group II $(P=.603)$. Postoperative peak serum creatinine levels were higher in Group I patients than Group II $(1.54 \pm 1.09 \mathrm{mg} / \mathrm{dL}$ and $1.18 \pm 0.70 \mathrm{mg} / \mathrm{dL}$, respectively; $P=.003)$. When results were compared according to the RIFLE stage, the 15 patients in Group I included seven patients (46.7\%) in RIFLE R, five patients $(33.3 \%)$ in RIFLE I, and three patients $(20 \%)$ in RIFLE F stage. Whereas 42 patients in Group II included 29 patients $(69.1 \%)$ in RIFLE R, 10 patients $(23.8 \%)$ in RIFLE I, and three patients $(7.1 \%)$ in RIFLE $F$ stage (RIFLE R, $P=.222$; RIFLE I, $P=.044$; RIFLE F, $P=.038$, respectively) (Figure).

Renal replacement therapy was used in $2.97 \%(\mathrm{~N}=10)$ of patients (seven patients were in Group I, and three patients were in Group II, $P<.001)$. The creatinine value before the commencement of RRT was $3.98 \pm 0.54 \mathrm{mg} / \mathrm{dL}$. RRT was started 33-52 hours after surgery and used for a maximum of five days. The mean creatinine level was $1.37 \pm 0.78 \mathrm{mg} /$ $\mathrm{dL}$ before hospital discharge and none of the patients became hemodialysis dependent.

The mean ICU time was $61.96 \pm 37.06$ hours in Group I and $51.63 \pm 25.93$ hours in Group II $(P=.018)$; inhospital stay time was $7.94 \pm 2.88$ days in Group I and 7.03 \pm 1.53 days in Group II $(P=.001)$. The intraaortic balloon pump (IABP) support was required in $3.9 \%$ of patients (five patients in Group I and eight patients in Group II, $P=.023)$. Prolonged ventilatory support was necessary for $3.6 \%$ of patients and the mean ventilatory support time was 9.06 \pm 6.79 in Group I and $7.40 \pm 3.67$ in Group II, $P=.013$ ) and one of these patients required a tracheotomy. The 30-day mortality was $2.1 \%(\mathrm{~N}=7$, four patients in Group I and three patients in Group II, $P=.009)$. All patients died due to low cardiac output and multiorgan failure, and these patients required RRT. 
DISCUSSION

In the present study, we analyzed the effect of preoperative SCH on AKI and RRT requirement after CABG. Acute kidney injury was observed in $16.9 \%$ of the patients in our study. Postoperative AKI occurred in 15 patients in Group I (SCH) and 42 patients in Group II (euthyroid). Logistic regression analysis revealing the presence of $\mathrm{SCH}$ preoperatively was shown to be associated with an increased incidence of postoperative AKI (OR, 0.363; 95\% CI, 0.181-0.727; $P=$ $.004)$. Renal dysfunction after cardiac surgery is a common complication; however, the exact mechanism still is unclear. Hypertension, DM, age, severe arteriosclerosis, and impaired left ventricular function are the known major preoperative risk factors for postoperative AKI [Doddakula 2007; Weerasinghe 2001; Chertow 1997]. SCH is suggested to affect vascular systems, such as decreased arterial compliance, increased systemic vascular resistance, endothelial dysfunction, coagulation, and atherosclerosis [Kahaly 2005; Cooper 2012; Cikim 2004]. The intraoperative causative mechanisms of AKI, during cardiac surgery, are $\mathrm{CPB}$ induced SIRS that results in the production of excessive ROS, ischemia-reperfusion that also leads to the generation of free oxygen radicals and hypoperfusion of the organs, mainly the kidneys [Haase 2007]. Hypothyroidism also is reported to prompt oxidative stress, inflammation, and result in enzymatic metabolism changes in renal tubules, thereby causing renal tubular injury [Suher 2005; Marfella 2011]. Thus, we hypothesized that through these effects of $\mathrm{SCH}$, it should further increase the risk of AKI after CABG. In our study, SCH was diagnosed in $14 \%$ of all patients; additionally, SCH was more common among females and older patients and these results were compatible with the literature [Garber 2012]. Our results showed that metabolic syndrome (MetS) was more common in SCH patients than in the euthyroid group.

Metabolic syndrome, like SCH, is a common problem in the general population and also in patients with cardiovascular disease. There is an ongoing debate about the link between SCH and MetS. It is reported that $\mathrm{SCH}$ was associated with MetS, especially among Asian populations [Yang 2016]. Obesity (BMI $>30 \mathrm{~kg} / \mathrm{m} 2)$, also a component of MetS, was reported to be more common in SCH patients in our study. It is known that obesity is associated with changes in thyroid hormones, and it also is known that hypothyroidism may induce obesity, thus it is stated that there is a bidirectional relationship between obesity and thyroid disease [Song 2019]. SCH is found to be also associated with hypertension, dyslipidemia, and Type 2 diabetes, in addition to obesity. However, our results did not show a significant difference between the groups regarding diabetes, dyslipidemia, and hypertension preoperatively.

In the literature, it is suggested that MetS and obesity $\left(\mathrm{BMI}>30 \mathrm{~kg} / \mathrm{m}^{2}\right)$ is associated with postoperative AKI after CABG [Tekeli 2016]. In the present study, MetS and obesity were shown to be independent risk factors for AKI after CABG (OR, 3.817; 95\% CI, 2.048-7.115; $P<.001$ and OR, 3.878 ; 95\% CI, 2.148-7.001; $P<.001$, respectively). Multivariate logistic regression analysis revealed that DM (OR, 4.975;
95\% CI, 2.707-9.145; $P<.001)$ also was another independent risk factor of $\mathrm{AKI}$ in the present study.

We compared the patients according to the severity of AKI and reported that the SCH group had a higher number of patients in RIFLE I and RIFLE F stages. Renal hemodynamics are demonstrated to be affected by thyroid hormones. Pre-renal effects of thyroid hormones are mediated by their influence on the renin-angiotensin system, cardiovascular system, and the renal blood flow. It is suggested that the intrarenal vasoconstriction may decrease renal blood flow and may lead to prerenal kidney injury [Klein 2001]. It is well known that CPB leads to low T3 syndrome. Iglesias et al. reported an association between AKI and low T3 syndrome, and they showed an improvement of renal function by an increase in serum T3 levels [Iglesias 2013]. These could explain the association of SCH and AKI in the present study. It is suggested that postoperative AKI requiring RRT has an overall mortality of 40-80\% [Lassnigg 2000]. It has an independent effect on early mortality and morbidity and also the quality of life in the short- and long-term. There are studies concerning treatment modalities for lowering the need for RRT [Iglesias 2013]. Continuous RRT aims to treat AKI by maintaining hemodynamic stability, acid-base, and electrolyte balances in critically ill patients with a very high risk of mortality. The present study demonstrates that RRT was required in $2.97 \%$ of patients. Seven patients were in Group I, and three patients were in Group II; this result was statistically significant. None of the patients became hemodialysis dependent. There is not a consensus regarding the timing and type of RRT to apply. The decisions regarding these factors were made together with our nephrologists in this study [Kunt 2009; Bouman 2002].

The mean ICU time, length of hospital stay, and mean ventilatory support times were statistically longer in Group I. This could be due to the increased use of RRT in SCH patients. Postoperative renal dysfunction affects not only mortality, but also the quality of life. AKI plays a vital role in postoperative mortality and morbidity in cardiac surgery patients. The rate of RRT is suggested to be $6 \%$ in patients with a high prevalence of AKI [Uchino 2005]. Among the patients who developed AKI, RRT was applied to $46.7 \%$ of the patients in our study group with $\mathrm{SCH}$ and $7.1 \%$ in the euthyroid group, where the difference was statistically significant. The overall 30-day mortality was $2.1 \%(\mathrm{~N}=7)$ four patients in Group I and three patients in Group II, where the difference was statistically significant. All of the patients died due to low cardiac output and required RRT. Hemodynamic instability in SCH patients, due to hypotension, increased vascular resistance, and decreased sodium reabsorption might explain this result.

The main strength of the study was that we could achieve statistically significant differences with this small number of $\mathrm{SCH}$ patients compared with euthyroid patients. There are some limitations of the study. First, the study design is retrospective. Second, in the present study, we don't know the postoperative levels of FT4 and FT3, so it was not possible to compare the prognosis of $\mathrm{SCH}$ and patients converted to the euthyroid state. 


\section{CONCLUSION}

AKI after CABG results in various postoperative complications and leads to prolonged hospitalization, and eventually increased costs as well as the increased rate of mortality. SCH is a common risk factor that showed a significant predictive effect on morbidity and mortality after CABG. Therefore, preoperative evaluation of thyroid function may be important to predict $\mathrm{AKI}$ a requirement for $\mathrm{RRT}$ after $\mathrm{CABG}$. SCH is a modifiable issue; if it is converted to euthyroid state and wellcontrolled, its dreadful effects after cardiac surgery might be controlled as well. Further, prospectively designed studies of thyroid hormone replacement in patients with $\mathrm{SCH}$ before cardiac surgery are warranted.

\section{REFERENCES}

Bellomo R, Ronco C, Kellum JA, Mehta RL, Palevsky P. 2004. Acute Dialysis Quality Initiative workgroup. Acute renal failure - definition, outcome measures, animal models, fluid therapy and information technology needs: the Second International Consensus Conference of the Acute Dialysis Quality Initiative (ADQI) Group. Crit Care 8:R204-12.

Bouman CS, Oudemans-Van Straaten HM, Tijssen JG, Zandstra DF, Kesecio lu J. 2002. Effects of early high-volume continuous venovenous hemofiltration on survival and recovery of renal function in intensive care patients with acute renal failure: a prospective, randomized trial. Crit Care Med 30:2205-11.

Chang YC, Chang CH, Yeh YC, Chuang LM, Tu YK. 2018. Subclinical and overt hypothyroidism is associated with reduced glomerular filtration rate and proteinuria: a large cross-sectional population study. Sci Rep. 8:2031.

Chertow GM, Lazarus JM, Christiansen CL, et al. 1997. Preoperative renal risk stratification. Circulation 95:878-84.

Cikim AS, Oflaz H, Ozbey N, Cikim K, Umman S, Meric M, Sencer E, Molvalilar S. 2004. Evaluation of endothelial function in subclinical hypothyroidism and subclinical hyperthyroidism. Thyroid. 14:605-9.

Cooper DS, Biondi B. 2012. Subclinical thyroid disease. Lancet 379:1142-54.

Cockcroft DW, Gault MH. 1976. Prediction of creatinine clearance from serum creatinine. Nephron 16:31-41.

Demirkılıç U, Kuralay E, Yenicesu M, et al. 2004. Timing of replacement therapy for acute renal failure after cardiac surgery. J Card Surg 19:17-20.

Doddakula K, Al-Sarraf N, Gately K, et al. 2007. Predictors of acute renal failure requiring renal replacement therapy post cardiac surgery in patients with preoperatively normal renal function. Interact Cardiovasc and Thorac Surg 6:314-8.

Garber JR, Cobin RH, Gharib H, et al. 2012. Clinical practice guidelines for hypothyroidism in adults: Cosponsored by the American Association of Clinical Endocrinologists and the American Thyroid Association. Endocr Pract 18: 988-1028.

Haase M, Haase-Fielitz A, Bagshaw SM, Ronco C, Bellomo R. 2007. Cardiopulmonary bypass-associated acute kidney injury: a pigment nephropathy? Contrib Nephrol 156:340-353.

Hall RI, Smith MS, Rocker G. 1997. The systemic inflammatory response to cardiopulmonary bypass: pathophysiological, therapeutic, and pharmacological considerations. Anesth Analg 85:766-82.
Iglesias P, Olea T, Vega-Cabrera C, Heras M, Bajo MA, del Peso G, et al. 2013. Thyroid function tests in acute kidney injury. J Nephrol. 1:164-72.

Kahaly GJ, Dillmann WH. 2005. Thyroid hormone action in the heart. Endocr Rev 26:704-28.

Kim EO, Lee IS, Choi YA, et al. 2014. Unresolved subclinical hypothyroidism is independently associated with progression of chronic kidney disease. Int J Med Sci 11: 52-9.

Kim YA, Park YJ. 2014. Prevalence and risk factors of subclinical thyroid disease. Endocrinol Metab 29:20-9.

Klein I, Ojamaa K. 2001. Thyroid hormone and the cardiovascular system. N Engl J Med. 7:501-9.

Kunt AT, Akgün S, Atalan S, Bitir N, Arsan S. 2009. Furosemide infusion prevents the requirement of renal replacement therapy after cardiac surgery. Anadolu Kardiyol Derg 9:499-504.

Lassnigg A, Donner E, Grubhofer G, Presterl E, Druml W, Hiesmayr M. 2000. Lack of renoprotective effects of dopamine and furosemide during cardiac surgery. J Am Soc Nephrol 11:97-104.

Liu KL, Lo M, Canaple L, Gauthier K, Del Carmine P, Beylot M. 2014. Vascular function of the mesenteric artery isolated from thyroid hormone receptor- $\alpha$ knockout mice. J Vasc Res. 51:350-9.

Marfella R, Ferraraccio F, Rizzo MR, Portoghese M, Barbieri M, Basilio C, Nersita R, et al. 2011. Innate immune activity in plaque of patients with untreated and L-thyroxine- treated subclinical hypothyroidism. J Clin Endocrinol Metab 96:1015-1020.

Michael UF, Barenberg RL, Chavez R, Vaamonde CA, Papper S. 1972. Renal handling of sodium and water in the hypothyroid rat. Clearance and micropuncture studies. J Clin Invest. 51:1405-12.

Mousa S, Hemeda A, Ghorab H, Abdelhamid A, Saif A. 2020. Arterial wall stiffness and the risk of atherosclerosis in Egyptian patients with overt and subcliinical hypothyroidism. Endocr Pract 26:161-6.

Saif A, Mousa S, Assem M, Tharwat N, Abdelhamid A. 2018. Endothelial dysfunction and the risk of atherosclerosis in overt and subclinical hypothyroidism. Endocr Connect 7:1075-80.

Song RH, Wang B, Yao QM, Li Q, Jia X, Zhang JA. 2019. The Impact of Obesity on Thyroid Autoimmunity and Dysfunction: A Systematic Review and Meta-Analysis. Front Immunol. 10:2349.

Suen WS, Mok CK, Chiu SW, et al. 1998. Risk factors for development of acute renal failure (ARF) requiring dialysis in patients undergoing cardiac surgery. Angiology 49:789-90.

Suher M, Koc E, Ata N, Ensari C. 2005. Relation of thyroid disfunction, thyroid autoantibodies, and renal function. Ren Fail 27 (6): 739-42.

Tekeli Kunt A, Parlar H, Findik O, Duzyol C, Baris O, Balci C. 2016. The Influence of Metabolic Syndrome on Acute Kidney Injury Occurrence after Coronary Artery Bypass. Heart Surg Forum. May 18;19:E099-103.

Uchino S, Kellum JA, Belloma R, et al. 2005. Acute renal failure in critically ill patients; a multinational, multicenter study. JAMA 294:813-8.

Weerasinghe A, Hornick P, Smith P, Taylor K, Ratnatunga C. 2001. Coronary artery bypass grafting in non-dialysis-dependent mild-to-moderate renal dysfunction J Thorac Cardiovasc Surg 121:1083-9.

Wikström L1, Johansson C, Saltó C, Barlow C, Campos Barros A, Baas F, Forrest D, Thorén P, Vennström B. 1998. Abnormal heart rate and body temperature in mice lacking thyroid hormone receptor alpha 1. EMBO J. 17:455-61.

Yang L, Lv X, Yue F, et al. 2016. Subclinical hypothyroidism and the risk 
of metabolic syndrome: A meta-analysis of observational studies. Endocr Res 41:158-65.

Zahler D, Izkhakov E, Rozenfeld KL, Ravid D, Banai S, Topilsky Y, Shacham Y. 2019. Relation of subclinical hypothyroidism to acute kidney injury among ST-segment elevation myocardial infarction patients undergoing percutaneous coronary intervention. IMAJ 21: 692-5.

Zhang L, Yang G, Su Z, Yang J. 2017. Correlation between subclinical hypothyroidism and renal function in patients with diabetes mellitus. Nephrology (Carlton) 22 (10): 790-5. 